\title{
Espaço em retalhos, alinhavar do tempo: a cidade e o campo em um conto de Monteiro Lobato
}

\author{
Juliana Santini \\ Doutoranda do Programa de Pós-Graduação \\ em Estudos Literários da Universidade Estadual \\ Paulista (UNESP), campus de Araraquara. \\ Bolsista FAPESP.
}

Resumo: Partindo do lugar ocupado pelo trágico na composição de um retrato da decadência, este trabalho analisa o significado da relação entre campo e cidade no conto "A colcha de retalhos", de Monteiro Lobato, considerando, ainda, a imagem do habitante dos espaços urbano e rural que se projeta dessa relaçāo.

Abstract: This work analyses the meaning of the relationship between field and city in the short story "A colcha de retalhos", by Monteiro Lobato, considering the place occupied by tragic elements in the composition of a literary image of people that live in urban and rural areas.

Palavras-chave: Urbano; rural; trágico; literatura brasileira

Keywords:Urban; rural; tragic; Brazilian literature 

Ao intitular "Doze mortes trágicas" seu primeiro livro de contos, atendendo à sugestão de Artur Neiva (AZEVEDO; CAMARGOS; SACCHETTA, 1997, p.111), Monteiro Lobato antecipa parte da atmosfera que define o conjunto de narrativas enfeixadas no volume. Malgrado a tragicidade, latente na maior parte das histórias, o que se tem é, antes, uma oscilação entre narrativas trágicas, cômicas ou que emparelham cômico e trágico em um mesmo enredo. A opção por essa composição oscilante, se em parte serve a certa superficialidade na composição dos personagens por se fundamentar em traços fortes, bem delimitados e esquematicamente exteriores, em parte atém-se à composição de um retrato de aspectos da realidade, que se desenha mais como um panorama do que como uma análise vertical desse espaço.

O significado dessa articulação - ou justaposição, se for considerado o fato de que cômico e trágico não chegam a se interpenetrar na estrutura dos contos - liga-se à composição de um riso que não se manifesta apesar do trágico, mas em consonância com ele: "Botei ultimamente quatro ovos novos, da nova fase: Pollice verso, O Matapau, O Estigma e O Comprador de Fazendas. Vou dar um livro inçado de dramas e mortes horrendas, mas com pantomima cômica no fim, como nos circos" (LOBATO, 1959, p.143). O comentário de Lobato a seu amigo correspondente, Godofredo Rangel, acena para um fio condutor da interpretação, que inicialmente se poderia fazer, da comicidade e da tragicidade nos contos de Urupês, a de um espetáculo em que gestos e movimentos estariam restritos à exterioridade de uma diversão ligeira e despreocupada:

[...] não se deve procurar, mesmo nos momentos mais felizes do contista, a categoria da profundidade, enquanto projeção de dramas morais que revelem um destino ou configurem uma existência. Lobato era escritor de outro estofo: sabia narrar com brilho um caso, uma anedota e sobretudo um desfecho de acaso ou violência. Daí decorrem seus riscos mais comuns: o ridículo arquitetado dos contrastes e o paroxismo patético não menos arquitetado dos finais imprevistos e sinistros. (BOSI, 1997, p.217) 
'As citações do conto "A colcha de retalhos" extraídas da 37. ed. de Urupês (2004), serão assinaladas de agora em diante pelo número da página.

A observação do crítico, embora, de modo acertado, insira o conto lobatiano em uma categoria diferente daquela que se fundamenta por uma análise psicológica profunda, peca por considerar o cômico e o trágico como elementos alheios à natureza do caso ou como traços a que se estende um valor negativo. A despeito do que afirma Alfredo Bosi (1997), pode-se considerar que a narrativa em forma de caso, atrelada ao esforço de "desliteralizar o texto" (LUCAS, 1989, p.75), articula-se ao trágico de modo a incorporar a violência que faz parte do cotidiano e do imaginário sertanejos, projetando-se, ainda, para a presença da morte e da marca inexorável do tempo em figuras humanas decrépitas, atadas à falência econômica e moral.

Essas imagens da falência constroem-se, nos contos de Lobato, em consonância com uma visão que tematiza o campo - tomado como espaço de decadência do caipira em paralelo com a esfera urbana - submetida a significativas transformações desde a Abolição da Escravatura, em 1888 -, de modo que, ao focalizar a "roça", o que se tem é, por extensão, um retrato em negativo da cidade. Essa abordagem, afinada a uma tendência característica de parte da prosa pré-modernista do período - preocupada em definir a síntese de um tipo sertanejo que se desenhava à margem do progresso - fundamenta grande parte da produção contística do autor paulista e garante a submissão de seus personagens a situações em que o homem é levado ao limite da existência, alinhavando à relação campo-cidade a parte da dimensão trágica de suas narrativas.

É o caso de "A colcha de retalhos" ', conto que apresenta a história de Pingo d'Água, jovem que vivia na roça, filha do sitiante José Alvorada, que deixou a cidade e adquiriu uma propriedade no campo, mas entrou em decadência e perdeu quase tudo o que possuía. O fio que sustenta a narrativa ata-se ao alinhavar de uma colcha de retalhos, costurada pela velha nhá Joaquina, avó da garota, que tecia, com retalhos de panos dos vestidos da menina, uma peça que seria o presente de casamento de Pingo. Na medida em se cose a colcha, são apresentados ao leitor não apenas os passos de Pingo d'Água - desde sua infân- 
cia até o momento em que partiu com um vizinho para a cidade, com o intuito de se prostituir - , mas também a situação de miséria e abandono a que estão submetidos os membros da família de Alvorada, que vê a mulher adoecer e morrer e presencia a tristeza dilacerante da sogra, com quem compartilha a dor da perda de Pingo.

Os fatos são apresentados por um narrador homodiegético, homem da cidade que tentara negociar as terras falidas de José Alvorada e, dois anos depois, tomou conhecimento do acontecido e se deslocou novamente para o sítio, com a intenção de confirmar a história da partida de Pingo d'Água. Sem participar dos acontecimentos que compõem a diegese, esse narrador articula-se duplamente na medida em que não somente entoa a voz que conta, mas também detém o olhar que se lança sobre a realidade narrada. Sob esse aspecto, "A colcha de retalhos" fundamenta-se sob o ponto de vista de um homem que não pertence ao espaço do campo: não nomeado, esse narrador desloca-se para o ambiente rural apenas duas vezes: a primeira, quando esperava negociar o sítio do Alvorada e obter lucro significativo com o plantio de milho; a segunda, para observar de perto o acontecimento nefasto que representou a falência completa da família.

A presença desse narrador citadino que se desloca para o espaço rural institui na narrativa a polaridade campo versus cidade, cisão que sustenta a natureza de seu relato e, ainda, o significado do elemento trágico na estruturação do texto. Tomada como ponto de partida, essa dualidade determina tanto as cores a serem utilizadas na descrição do espaço pela voz que o emoldura quanto a interpretação que se faz do modo de vida roceiro, impregnado pela ideologia e pelos costumes de quem pertence a outra esfera social e econômica. Desse modo, oscilam na narração desse homem da cidade a subjetividade de descrições espaciais impregnadas por um exotismo que encontra respaldo no olhar civilizado sobre o campo e a objetividade de comentários que trazem à tona a situação de abandono em que vive o roceiro.

A metáfora que abre o conto antecipa a subjetivi- 
dade de um olhar que descreve o espaço a partir de um ponto de vista exótico, impressionista na medida em que justapõe cores e formas: "Por estes dias de março a natureza acorda tarde. Passa as manhãs embrulhada num roupão de neblina e é com espreguiçamentos de mulher vadia que despe os véus da cerração para o banho de sol" (p.45). A leveza da manhã contrasta com a decrepitude das áreas que deveriam servir à produção e à venda de produtos, mas que são consumidas por mato e ervas daninhas. A atitude do narrador diante do abandono, menos subjetiva e calcada em uma observação mais apurada, resvala para a descrição objetiva do espaço, alheia à metáfora idealizadora do princípio da narrativa:

O velho pomar, roído de formiga, morrera de inanição; na ânsia de sobreviver, três ou quatro laranjeiras macilentas, furadas de broca e sopesando o polvo retrançado da erva-de-passarinho, ainda abrolhavam rebentos cheios de compridos acúleos. Fora disso, mamoeiros, a silvestre goiaba e araçás, promiscuamente com o mato invasor que só respeitava o terreirinho batiço, fronteiriço à casa. Tapera quase e, enluradas nela, o que é mais triste, almas humanas em tapera. (p.47)

A objetividade da constatação do abandono é quebrada pela metáfora final da alma humana que se fez tapera, ponto de revelação não apenas da extinção da produtividade da família, mas também da morte da humanidade que os definia. Imagem que representa a decadência do homem no espaço rural, a tapera - propriedade em ruínas - confunde seus escombros com as ruínas dos Alvorada, incapazes de promover a prosperidade das terras que adquiriram quando migraram da cidade para o campo. Notese, aqui, que os membros da família de José Alvorada não pertencem ao espaço rural, não são caipiras - como anuncia o narrador (p.46) -, mas são citadinos, nascidos na cidade, que deixaram os esquadros urbanos para empreender o cultivo de uma pequena propriedade rural.

As causas da falência não são analisadas ou colo- 
cadas em questão pelo narrador, que apenas esboça os contornos da trajetória de empobrecimento e abandono da família e das terras, mas a figura de José Alvorada, enquanto homem civilizado que passa a habitar a roça, carrega consigo a extensão da marginalização e pobreza a que estaria submetida qualquer tentativa de prosperidade no campo. A escassez de recursos e a ausência de incentivo para que a produção fosse modernizada ficam implícitas no comentário que sumariza o malogro da família: "[...] a vida lhes correu áspera na luta contra as terras ensapezadas e secas, que encurtam a renda por mais que dê de si o homem" (loc.cit.).

Narrativa de contrastes, a carência da propriedade opõe-se ao impulso empreendedor do narrador, interessado em cultivar as terras de Alvorada. Entre as atitudes de Zé e do narrador, desenha-se um hiato que traceja o atavismo daquele que se encontra no espaço rural e a busca por lucros de quem possui recursos e técnica mais avançada de plantio: "Três alqueires, só no bom. Talvez quatro. A noventa por um - nove vezes quatro trinta e seis; trezentos e sessenta alqueires de oito mãos. Descontadas as bandeiras que o porco estraga e o que comem a paca e o rato..." (loc.cit.).

Mas o raciocínio matemático, que ilustra a mentalidade capitalista do negociante, acaba por esbarrar na falta de motivação do roceiro, debilitado e cansado de acumular prejuízos: "Um perrengue como eu não pensa mais nisso, não. Quando era gente, muitos peguei a sessenta e não me arrependi. Mas hoje..." (p.50). Fracassado o negócio, o narrador conversa com a velha Joaquina, que mostra ao rapaz a colcha de retalhos que está preparando para a neta, toma um café ralo feito com os resíduos do produto que fora escolhido, e retorna para o "bairro", onde permanece por mais dois anos, tendo apenas notícia da morte da esposa de José Alvorada, distância que o faz esquecer da "[...] imagem daqueles humildes urupês" (loc.cit.).

Dois momentos distintos cindem a narração empreendida por este homem que observa com olhar diverso a vida do caboclo urupê: o primeiro deles diz respeito a 
2 A edição do estudo de Gerard Genette, utilizada neste artigo, é a primeira em língua portuguesa. Foi publicada sem data pela Editora Vega. A terceira edição é de 1995. essa visita em que o narrador tenta negociar com José Alvorada, enquanto o segundo constrói-se a partir de seu retorno ao sítio, depois de ter recebido a notícia da partida de Pingo d'Água, "furtada" por um vizinho para que se prostituísse na cidade. Esses dois estratos temporais, costurados um ao outro pela fala do narrador, são separados por uma elipse, que cinde um e outro tempo pela suspensão de parte do tempo da história (GENETTE, s.d., p.106) ${ }^{2}-$ os dois anos que o narrador esteve distante dos Periquitos: "Transcorreram dois anos sem que eu tornasse aos Periquitos. Nesse intervalo Sinh'Ana faleceu. Era fatal a dor que respondia na cacunda" (loc.cit.).

O retorno do narrador ao sítio, curioso pela notícia que recebera acerca de Pingo d'Água, constitui uma espécie de reconstrução do tempo que fora suprimido pela elipse. Chegando à propriedade de Zé Alvorada, o narrador não o encontra; põe-se a conversar com a velha Joaquina, que refaz o passado alinhavado aos retalhos da colcha. Cada retalho, pedaço de outrora mantido vivo no presente, é apresentado ao narrador como parte da trajetória de perdição de Pingo, como se o vestido evocado pelo tecido fosse responsável também pela exposição da moça à sedução e aos perigos da cidade:

- Este é novo. Já tinha feito quinze anos quando o vestiu pela primeira vez num mutirão do Labrego. Não gosto dele. Parece que a desgraça começa aqui. Ficou um vestido muito assentadinho no corpo, e galante, mas pelas minhas contas foi o culpado do Labreguinho engraçar-se da coitada. Hoje sei disso. Naquele tempo nada suspeitava. (p.52)

Metáfora do tempo que se esvai, a colcha de retalhos não deixa de representar os liames que ligam a família de José Alvorada aos ecos de um tempo irremediavelmente perdido. A obsolescência da propriedade, assim como a estagnação de seus habitantes e os modos de produção arcaicos, geradores mais de prejuízos do que de recursos capazes de prover sequer o sustento digno da família, envolta pela pobreza e pela carência, submetem os 
personagens do sítio dos Periquitos a uma dimensão temporal alheia ao presente, como se o tempo, costurado à colcha, tivesse cessado seu curso apenas na esfera de vida da família: "Confrangia-me o coração aquele ermo onde tudo era passado - a terra, as laranjeiras, a casa, as vidas, salvo - trêmulo espectro sobrevivente como a alma da tapera - a triste velhinha encanecida, cujos olhos poucas lágrimas estilavam, tantas chorava" (p.51). Também retalhada em dois segmentos, a narrativa recupera em sua estrutura essa mesma idéia de retalhos de tempo que se costuram, fazendo do passado cerzido ao presente mote e matéria de sua forma.

A atmosfera de desgraça que envolve os personagens roceiros do conto adensa-se na medida em que à falência econômica agrega-se o rebaixamento moral, levado a cabo pela partida de Pingo d'Água para a cidade. O deslocamento de Pingo para o espaço urbano reinstaura a problemática do contraste entre campo e cidade, já instituída pela natureza da figura que narra e focaliza os acontecimentos que compõem a diegese. Se a trajetória de Pingo marca a ameaça representada pelos contornos da cidade, que degrada e devora - colocando em cena a questão que envolve a problemática do progresso enquanto fator negativo-, a anterior saída da família do espaço urbano a fim de comprar uma propriedade no campo - movimento que não deixa de representar, no limite, uma espécie de fuga da cidade - aponta, ao contrário, para a falência do espaço rural, já que é na roça que a família encontra a derrocada.

O trânsito dos personagens entre o urbano e o rural demarca e reafirma os contrastes que fundamentam a narrativa de "A colcha de retalhos", de modo que à tentativa de conservar retalhos de tempo cosidos à colcha corresponde o retalhamento de espaços, a que os personagens permanecem tão costurados quanto ao tempo que se esvaiu. Nesse sentido, note-se que José Alvorada percorre um caminho diverso daquele que configurou o movimento migratório do princípio do século XX no Brasil: enquanto a industrialização fomentou a urbanização dos grandes centros e intensificou a 
saída de pessoas do campo para a cidade, Zé embrenhase em uma estrada que conduz à contramão do desenvolvimento e deixa a cidade para cultivar uma propriedade na zona rural.

Malgrado a frustração do intento de prosperar à margem do urbanismo, a família de José Alvorada permanece atada ao campo, de modo a ensimesmar-se na vida precária que a assolava. A flexibilidade que sustentou o movimento de outrora se anula, agora, na recusa de retornar ao espaço original ou de permitir que a modernidade penetre no campo, traço reiterado pela figura de Sinh'Ana, esposa de Zé, que sustentava o enraizamento na terra ao afirmar que uma mulher deveria ir à cidade apenas para ser batizada, abençoada no casamento e, por fim, enterrada. E é também Sinh'Ana quem tenta retirar de Pingo qualquer possibilidade de mobilidade, afastando-a, inclusive, da alfabetização: "Ler? Escrever? Patacoadas, falta de serviço, dizia a mãe. Que lhe valeu a ela ler e escrever que nem uma professora, se des'que casou nunca mais teve jeito de abrir um livro? Na roça, como na roça" (p.47).

A atitude da família de José Alvorada, que não apenas se estagnou, mas também pensava em viver no mato, "como bicho", pontua tanto a inadequação dos personagens àquele espaço quanto a recusa ao universo urbano, responsável, no limite, pela desgraça de Pingo d'Água. A imigração de Alvorada da cidade para o campo, além de sua posição contrária a qualquer tipo de remorso pelo espaço deixado para trás, anula a dialética apontada por José Paulo Paes (1985) na construção de um imaginário - na música sertaneja e também na literatura - que se baseia no movimento de abandono do espaço rural para fixação no ambiente urbano:

Se a componente de base do bovarismo é a linha de fuga, configuração do impulso de dentro para fora que leva do familiar para o exótico, nem por isso se lhe pode ignorar, componente secundária, mas dialética, a linha de retorno por onde circula o impulso contrário, que vai do exótico, agora familiar pela proximidade, rumo ao familiar tornado exótico pela distância. (PAES, 1985, p.251) 
É fato que, no texto de Lobato (2004), não se poderia realizar qualquer manifestação da "síndrome pastoral" apontada por Paes (1985) em seu artigo, justamente porque o trajeto dos Alvorada realiza-se em um caminho inverso àquele discutido pelo autor. Entretanto, no que diz respeito à configuração de um sentimento de nostalgia que justifique a criação de uma imagem idealizada - ou ao menos valorizadora - do espaço deixado para trás, a recusa dos personagens conduz à negação do espaço urbano e de tudo o que ele representaria naquele contexto, de modo que se poderia pensar em uma louvação, por compensação, do espaço rural. A questão é que isso também não ocorre, ou seja, à margem do progresso e da urbanização, os personagens não encontram na roça um sistema que os encaixe, de maneira que se tece uma inadequação permanente, da qual é impossível se esquivar.

A dimensão trágica que perpassa toda a narrativa liga-se a essas duas esferas de estagnação da vida dos personagens: de um lado, o retalhamento do espaço e a incapacidade de prosperar tanto na cidade quanto na roça; de outro, a prisão a ưm momento do passado em que a decadência ainda não assolara a família, época da infância de Pingo d'Água, fragmento temporal entretecido à metáfora da colcha que intitula o conto. A falência dos personagens, tanto do ponto de vista individual quanto coletivo, cristaliza-se nos fios alinhavados à colcha que, a despeito de restituir o passado no presente, é incapaz de estender o fio da vida e afastar a morte, de modo que é justamente o tom lúgubre da perda que tinge toda a narrativa a partir do segundo momento em que o narrador se dirige aos Periquitos, restituindo a desgraça dos Alvorada na medida em que, também ele, funciona como unificador de espaços - o urbano e o rural - e tempos, já que o retorno ao sítio representa, no limite, a reconstrução do estrato temporal que fora suprimido pela elipse de dois anos, que marca e define a estrutura da narrativa.

Os contrastes demarcados pela fala do narrador e pela oposição de tempos e espaços no interior da narrativa compõem um conjunto em que a realidade é abarcada 
não em sua totalidade, mas a partir de um estrato que a representa em sua aridez e decadência. Assim como a colcha de retalhos constitui-se como uma porção metonímica do tempo, o sítio dos Alvorada é, antes, um microcosmo da situação de abandono e escassez de recursos da "roça", área que não pertence aos esquadros urbanos, mas também não pode ser considerada "sertão" ou "mato", já que situada em um ponto intermediário entre ambos justamente por ser povoada e explorada, onde se espera que haja o mínimo de modernização necessária ao cultivo de produtos agrários.

Sob esse aspecto, o modo de composição de "A colcha de retalhos" não deixa de confirmar o olhar realista que o autor reclamava para si ao explorar contrastes que, justapostos, compõem um retrato abrangente da realidade considerada. Monteiro Lobato não promove uma reflexão profunda acerca das condições que conduziram à decadência do espaço rural desenhado em sua narrativa, mas traceja um panorama que revela as diferenças e desigualdades desse espaço. A estrutura da narrativa, que contrasta tempos e espaços por meio da construção de dois sketches unidos pela fala do narrador, articula-se à proposta do autor de reduzir a amplitude do discurso em favor da condensação da informação narrada, princípio que se exibe em grande parte do "projeto estético" que se pode depreender da correspondência de Lobato a Rangel: "O fim visado num romance deve ser o máximo de impressão no leitor com o mínimo de meios. É neste sentido que voga o meu barco. Progrido com 'concentração', fujo sistematicamente à 'diluição'” (LOBATO, 1959, p.137).

A propensão à síntese e à condensação, articulada ao "conto-estopim" lobatiano, congrega-se ao efeito trágico na constituição de um desfecho marcado pelo absurdo da existência e pela situação de atavismo em que se encontram os personagens diante de suas vidas: "As personagens de Lobato são trágicas porque a mão tirana do enunciador as abandona nas suas condições. Elas são excessivas na sua fragilidade e/ou decadência" (MARCHEZAN, 1994, p.174). Esse excesso na representação da fragilidade e da decadência dos 
personagens de Monteiro Lobato não deixa de estar em consonância com a natureza caricaturesca de sua construção que, se em alguns casos, manifesta-se alheia ao riso que a define, não chega a perder o traço esquemático por meio do qual é possível delinear a realidade a partir de uma caracterização disforme e exagerada daquilo que se quer colocar em cena.

Como marionetes que permanecem aquém de seu destino, aos personagens de "A colcha de retalhos" é negada a consciência de sua condição, de modo que ao trágico da existência une-se, ainda, a dimensão trágica da impossibilidade de ação. Nesse sentido, nota-se que os personagens lobatianos são construídos em uma esfera que os afasta da possibilidade de agir, sendo o atavismo - desde os artigos "Velha praga" e "Urupês", de 1914, em que Jeca Tatu tinha a preguiça apontada como causa de seu fracasso - um de seus traços mais característicos. Se a imagem do caipira, transposta do jornal O Estado de São Paulo para as páginas do volume Urupês, mantém a ausência de ação como atributo definidor do comportamento do roceiro, há que se notar uma diferença que separa uma e outra figura a partir de um aspecto qualitativo essencial: José Alvorada não é um caipira, não nasceu na roça, mas mudou-se para o espaço rural após adquirir o sítio dos Periquitos.

Sob esse aspecto, a falência que anteriormente estava reservada ao "piolho da terra" estende-se à figura de um citadino, de modo que a ausência de ação também se alarga e passa a ocupar não apenas a esfera de vida do caipira. É fato que os contos de Urupês não se esquivam do lastro ideológico que marcou a construção da primeira versão do Jeca Tatu, estando ainda a imagem do caipira impregnada pela visão do fazendeiro interessado em prosperar, mas há que se considerar, na análise de contos como "A colcha de retalhos", um ponto de vista um pouco menos determinado, já capaz de ver como um "descalabro" (p.47) a situação marginal do roceiro, a quem eram vetados o progresso, a modernização, a civilização.

Grande parte da interpretação da crítica em relação ao caipira lobatiano, como uma imagem calcada no 
preconceito e na falta de observação da realidade, justifica-se por essa ausência de atitude do personagem, lida muitas vezes como atributo reiterativo da preguiça que estigmatizou o Jeca Tatu. Deve-se considerar, entretanto, que, na superficialidade do modo de composição lobatiano, não coube a reflexão acerca da situação a que foram expostos seus personagens, pelo contrário, a narrativa de Lobato é, antes, um retrato plano - sem profundidade ou densidade - de uma situação que, outrora mascarada pela idealização e pelo exotismo românticos, era ainda mantida pela prosa ornamental do período.

Nesse estado de coisas, o trágico articula-se à construção de um panorama em que o caipira e o citadino são observados sob um mesmo eixo de interpretação - sem maior profundidade de análise - na medida em que se comporta não como um elemento gerador de uma reflexão vertical acerca das condições dos personagens e do meio que as envolve, mas como fim que alinhava em um mesmo fio os pontos que perpassam a narrativa: a decadência da família Alvorada na roça, a morte de Sinh'Ana, a prostituição de Pingo d'Água na cidade e, por fim, a morte da velha Joaquina, que não teve atendido seu último pedido, o de ser enterrada com a colcha de retalhos como mortalha. 


\section{Referências}

AZEVEDO, C. L.; CAMARGOS, M.; SACCHETTA, V.

Monteiro Lobato. um furacão na Botocúndia. São Paulo: Editora

Senac, 1997.

BOSI, Alfredo. História concisa da literatura brasileira. 35.

ed. São Paulo: Cultrix, 1997.

GENETTE, Gerard. Discurso da narrativa. Tradução

Fernando Cabral Martins. Lisboa: Vega, s.d.

LOBATO, Monteiro. A barca de Gleyre. 9. ed. São Paulo:

Brasiliense, 1959. Tomo 2.

- Urupês. 37. ed. São Paulo: Brasiliense, 2004.

LUCAS, Fábio. Do barroco ao moderno. São Paulo: Ática, 1989.

MARCHEZAN, L. G. O espaço no conto regionalista brasileiro. 1994. 262 f. Tese (Doutorado em Teoria Literária) Faculdade de Filosofia, Letras e Ciências Humanas, Universidade de São Paulo, São Paulo, 1994.

PAES, José Paulo. Arcádia revisitada. In: . Gregos e baianos. São Paulo: Brasiliense, 1985. p. 242-253. 